\title{
Erythema Multiforme: Challenging Diagnosis for Internist
}

\section{Mohammed A Simbli*}

Division of Nephrology, Department of Medicine, King Khalid University Hospital, King Saud University, Riyadh, Saudi Arabia

\begin{abstract}
Erythema Multiforme (EM) is an acute, immune-mediated condition characterized by the appearance of distinctive target like lesions on the skin. The lesions are often accompanied by erosions or bullae involving the oral, genital and/or ocular mucosa. We report a case of Erythema Multiforme minor (EMm) who initially presented with a non healing bleeding target like lesions over the upper lip and latter developed target lesions on both hands.
\end{abstract}

Keywords: Erythema multiforme; Mucocutaneous disorder; Steroid

\section{Introduction}

Erythema Multiforme (EM) is an acute, immune-mediated condition characterized by the appearance of distinctive target like lesions on the skin. It is characterized by acrally distributed, distinct target like lesions with concentric color variation, sometimes accompanied by oral, genital, or ocular mucosal erosions or a combination of these [1]. Although EM is usually self-limiting, frequent episodes over the course of years can lead to recurrent disease in a subset of patients [2]. EM minor (EMm) is without mucosal disease and EM Major (EMM) involves mucosa.

Despite being often caused by, or at least associated with, infection or drug therapy, the pathogenic mechanism of EM remains unclear, and as a consequence there are no evidence-based, reliably effective therapies. A variety of factors have been implicated in the pathogenesis of EM. Herpes simplex virus being the most frequent precipitator [3-5]. Other factors include Mycoplasma infection, medication use, autoimmune disease, radiation, immunization, and menstruation.

We report a case of Erythema Multiforme minor (EMm) who presented with a non healing target like lesion over his upper lip and after a gap of about two weeks developed distinct lesions in both hands. It can be a challenge for an internist to diagnose EMm presenting first time with minimal skin manifestations.

\section{Case}

A 47 year old Kashmiri male presented with a black coin shaped lesion over the upper lip in midline, of two weeks duration (Figure 1). The patient denied any history of fever, rigors, sweating, cough, sputum production, diarrhea, loss of weight. He is married and has no history of extra-marital relation or high risk sexual behavior. No contact with a sick person or history of taking any medication. Other than lesions on upper lip his general physical examination and systems

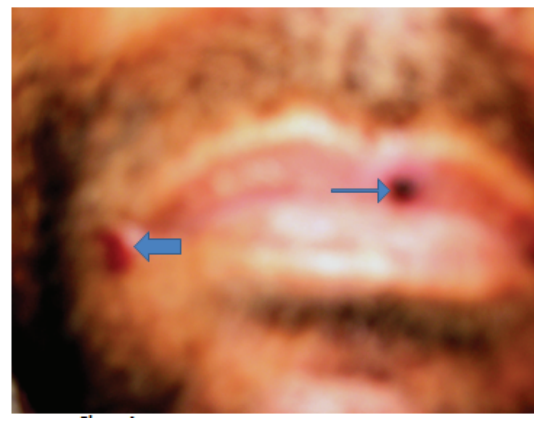

Figure 1: Target like lesion over upper lip. review was normal. He was prescribed topical antiviral (acyclovir) and antibacterial medication with no benefit. Subsequently topical steroids were prescribed and lesion showed no signs of healing. The lesions were friable and would bleed, making one to consider other possibilities i.e. malignancies, Sexually Transmitted Disease (STD), chronic infections viz. tuberculosis. He had bleeding from excoriation of nasal mucosa. Patient was apprehensive for none healing of lesions.

His initial investigations were CBC: hemoglobin $13 \mathrm{gm} / \mathrm{dL}, \mathrm{WBC}$ $5.6 \times 10^{9}$, neutrophils $80 \%$, lymphocytes $18 \%$, monocytes $2 \%$, Platelet $230 \times 10^{9}$, ESR $25 \mathrm{~mm} 1$ st hour. U\&E: urea $22 \mathrm{mg} / \mathrm{dL}$, creatinine $0.8 \mathrm{mg} /$ dL, Glucose 93 mg/dL, Biluribin 1 mg/dL, ALT 47 IU/L, AST 35IU/L. Urinalysis: normal. Chest X Ray: Normal.

As we were contemplating biopsy from lip lesion he developed target like lesions on both hands. He also complained of discomfort in hands associated with pruritis and heat intolerance. The lesions were present over palms as well as over back side of hands. They were round erythematosus papules with a dusky central area, a dark red inflammatory zone, and an erythematosus halo on the extreme periphery of the lesion (Figures 2 and 3). The lesions were classical of EMm and biopsy was not considered necessary now. He was treated with oral prednisolone $1 \mathrm{mg} / \mathrm{kg}$ for ten days and the lesions disappeared from lip as well as from hands. The healing was followed by peeling off of skin from hands.

\section{Discussion}

EM has been classified into a number of variants, mainly minor and major forms. EM minor (EMm) is mainly a cutaneous disease. Typical and/or raised atypical target lesions are the hallmark. Disease involves less than $10 \%$ of the body surface area. Lesions are often symmetrical in distribution, with a predilection for the extensor surfaces of the extremities. Mucosal involvement is uncommon, when present, only one site is affected, most commonly the mouth. EM Major (EMM) typically involves two or more mucous membranes with more variable skin involvement. Symmetrically distributed typical cutaneous target lesions and/or atypical raised target lesions are the hallmark. Oral lesions are usually widespread and severe [6].

*Corresponding author: Mohammed A Simbli, Division of Nephrology, Department of Medicine, King Khalid University Hospital, King Saud University, Riyadh, Saudi Arabia, E-mail: mohdamin1126@yahoo.com

Received May 20, 2013; Accepted June 14, 2013; Published June 17, 2013

Citation: Simbli MA (2013) Erythema Multiforme: Challenging Diagnosis for Internist. J Clin Case Rep 3: 285. doi:10.4172/2165-7920.1000285

Copyright: (c) 2013 Simbli MA. This is an open-access article distributed under the terms of the Creative Commons Attribution License, which permits unrestricted use, distribution, and reproduction in any medium, provided the original author and source are credited. 


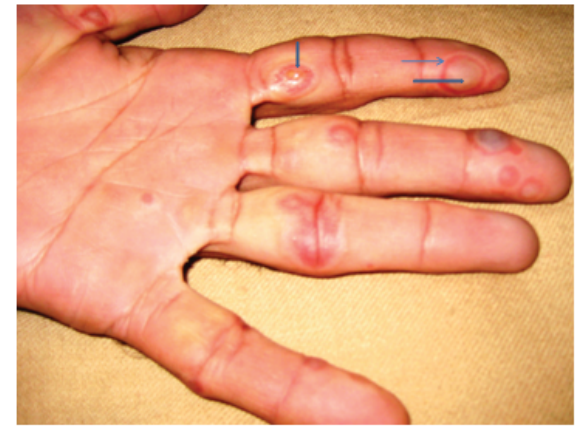

Figure 2: Note the central blister, dark red inflammatory zone, surrounded by pale ring of edema typical of erythema multiform.

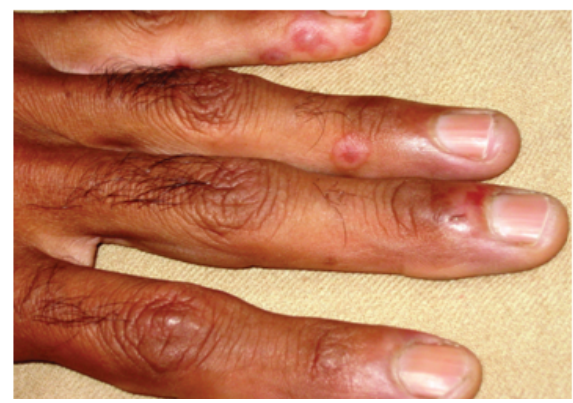

Figure 3: Lesions over dorsum of hand

EM is a disorder that reacts primarily to antigens that are induced by exposure to microbes or drugs [7] and has been reported to be triggered by numerous microbial agents, particularly viruses, mainly Herpes Simplex Virus (HSV), which is implicated in up to $70 \%$ of recurrent cases [8]. In one study, it has been reported that $71 \%$ of the EMm/EMM attacks were precipitated by a preceding HSV infection [9], particularly herpes labialis [10].

No specific objective markers or criteria are required for a diagnosis of EM. The important clues to diagnosis continue to be the clinical history and clinical findings. Pertinent components of the history include: (i) an acute, self-limiting or episodic course (ii) signs and symptoms of associated infections, such as HSV or M. pneumonia infection and (iii) a history of the use of new medications. Clinical clues to diagnosis include the presence of target lesions, raised atypical papules or mucosal involvement, or a combination of these. Laboratory studies and skin biopsies are not required in all cases of EM [11]. As in our case we cancelled the skin biopsy, when classical lesions appeared. However, laboratory evaluation and histopathology may assist in confirming the diagnosis, determining the inciting factor and ruling out other diseases in the differential diagnosis.

Classic EM is a self-limiting skin disease. However, some patients have frequent episodes over years (recurrent EM) and, rarely, others may have continuous uninterrupted disease (persistent EM). The lesions of EM typically appear over 3-5 days and resolve over 1-2 weeks $[4,12]$. The period from disease onset to resolution is $<4$ weeks. However, in severe cases of EM with mucosal involvement, resolution may require up to six weeks $[4,12]$. Itching and burning of skin, swelling of hands and feet, pain caused by mucosal erosions, and poor oral and fluid intake are important causes of morbidity in EM [4]. The lips tend to become swollen and show diagnostically distinctive bloody encrustations (Figure 1). Target lesions may be seen on the lip but rarely on the intraoral mucosa [7]. Our patient had itching as well as burning sensation in both hands which persisted after healing of lesions. Although the skin lesions do not lead to scarring, a resultant post-inflammatory hyper pigmentation may persist for months after disease resolution [12]. Other mucosal surfaces including ocular, nasal, pharyngeal, laryngeal, lower respiratory, and anogenital may be involved.

The management of EM can be difficult. An important element in EM treatment is the discontinuation of all inciting factors. In addition, disease management depends on other factors, such as the presence of mucosal disease, the development of recurrent disease and overall disease severity. Antiviral agents may be indicated in herpes associated EM, and a 5 day course of acyclovir $200 \mathrm{mg}$ five times daily at the first sign of lesions, or $400 \mathrm{mg}$ four times daily for 6 months, or continuous treatment using valacyclovir, $500 \mathrm{mg}$ twice a day, is useful for prophylaxis [13]. In cases of Mycoplasma pneumonia infection, appropriate antibiotic therapy should be considered if the patient is symptomatic [14]. Tetracycline $250 \mathrm{mg}$ four times a day for at least 1 week may be indicated in EM related to Mycoplasma pneumonia.

Corticosteroids are the most commonly used drugs in the management of EM, despite the lack of evidence. EM may respond to topical corticosteroids. Our patient's lip lesion which was initially treated empirically with week corticoid hydrocortisone for one week did not respond. Patients with EMM should be treated with systemic corticosteroids (prednisolone $0.5-1.0 \mathrm{mg} / \mathrm{kg} /$ day tapered over $7-10$ days) or azathioprine, or both or other immunomodulatory drugs such as cyclophosphamide, dapsone, cyclosporine, levamisole, thalidomide or interferon-a [15]. Cyclosporine given intermittently may control recurrent EM [9]. The lesions over lip and hands responded well to oral prednisolone at $1 \mathrm{mg} / \mathrm{kg} / \mathrm{day}$ for ten days period in our case. He also needed antihistamines for uncomfortable itching of hands.

\section{Conclusion}

It can be quite frustrating both for physician and patient when a lesion over lip is not responding to usual topical treatment like antiviral, steroid, antibiotics, for possible common etiologies at this site. However diagnosis and treatment gets much clear when the classical lesions appear over the extremities such as hands and extensor surface of arms. It requires high degree of suspicion and knowledge about usual course of Erythema Multiforme presenting first time.

\section{References}

1. Assier H, Bastuji-Garin S, Revuz J, Roujeau JC (1995) Erythema multiforme with mucous membrane involvement and Stevens-Johnson syndrome are clinically different disorders with distinct causes. Arch Dermatol 131: 539-543.

2. Wetter DA, Davis MD (2010) Recurrent erythema multiforme: clinica characteristics, etiologic associations, and treatment in a series of 48 patients at Mayo Clinic, 2000 to 2007. J Am Acad Dermatol 62: 45-53.

3. French LE, Prins C (2008) Erythema multiforme, Stevens-Johnson syndrome and toxic epidermal necrolysis. In: Bolognia JL, Jorizzo JL, Rapini RP, eds. Dermatology, (2nd edn), St Louis, MO: Mosby Elsevier.

4. Huff JC, Weston WL, Tonnesen MG (1983) Erythema multiforme: a critica review of characteristics, diagnostic criteria, and causes. J Am Acad Dermatol 8: 763-775.

5. Weston WL (2005) Herpes-associated erythema multiforme. J Invest Dermato 124: xv-xvi.

6. Al-Johani KA, Fedele S, Porter SR (2007) Erythema multiforme and related disorders. Oral Surg Oral Med Oral Pathol Oral Radiol Endod 103: 642-654.

7. Ayangco L, Rogers RS 3rd (2003) Oral manifestations of erythema multiforme Dermatol Clin 21: 195-205. 
8. Carrozzo M, Togliatto M, Gandolfo S (1999) Eritema multiforme. Un fenotipo alterations in the HSV-specific T-cell response. Br J Dermatol 138: 952-964.

9. Schofield JK, Tatnall FM, Leigh IM (1993) Recurrent erythema multiforme: clinical features and treatment in a large series of patients. Br J Dermatol 128: 542-545.

10. Kokuba H, Imafuku S, Huang S, Aurelian L, Burnett JW (1998) Erythema multiforme lesions are associated with expression of a herpes simplex virus (HSV) gene and qualitative alterations in the HSV-specific T-cell response. $\mathrm{Br}$ J Dermatol 138: 952-964.

11. Sokumbi O, Wetter DA (2012) Clinical features, diagnosis, and treatment of erythema multiforme: a review for the practicing dermatologist. Int J Dermato 51: 889-902.

12. Huff JC (1985) Erythema multiforme. Dermatol Clin 3: 141-152.

13. Siegel MA, Balciunas BA (1994) Oral presentation and management of vesiculobullous disorders. Semin Dermatol 13: 78-86.

14. Roujeau JC (2008) Erythema multiforme. In: Wolff K, Goldsmith LA, Katz SI, et al. eds. Fitzpatrick's Dermatology in General Medicine, ( $7^{\text {th }}$ edn), NY: McGrawHill, New York

15. Stewart MG, Duncan NO $3^{\text {rd }}$, Franklin DJ, Friedman EM, Sulek M (1994) Head and neck manifestations of erythema multiforme in children. Otolaryngol Head Neck Surg 111: 236-242. 